\title{
Influence of cold forging and annealing on microstructure and mechanical properties of a high-Mn TWIP steel
}

\author{
P. Kusakin ${ }^{1}$, A. Kalinenko ${ }^{1}$, K. Tsuzaki ${ }^{2}$, A. Belyakov $^{1}$, R. Kaibyshev ${ }^{1}$ \\ ${ }^{1}$ Belgorod State University, Pobeda 85, Belgorod 308015, Russian Federation \\ ${ }^{2}$ Kyushu University, Department of Mechanical Engineering, Fukuoka 819-0395, Japan
}

Received 11 April 2016, received in revised form 28 June 2016, accepted 29 June 2016

\begin{abstract}
The influence of cold biaxial forging and annealing on the microstructure evolution and mechanical properties of Fe-18Mn-0.6C-0.1N TWIP steel was investigated. The microstructure after thermomechanical treatment was examined by means of scanning electron microscopy (SEM) with electron back-scatter diffraction (EBSD) analyzer and transmission electron microscopy (TEM). The microstructure containing a high density of deformation twins was evolved by cold forging. Then, the deformation microstructure was recovered or partially recrystallized during subsequent annealing for $1 \mathrm{~h}$ at 673 or $873 \mathrm{~K}$, respectively. The cold biaxial forging followed by partial recrystallization resulted in a very attractive combination of mechanical properties. The yield strength and the ultimate tensile strength of the steel after cold biaxial forging were 1320 and $1540 \mathrm{MPa}$, respectively, with elongation of $6 \%$. On the other hand, the yield and ultimate tensile strengths of 770 and $1110 \mathrm{MPa}$, respectively, and elongation about $40 \%$ were obtained after partial recrystallization. The as-forged and recovery annealed samples showed fatigue limit of 600 and $550 \mathrm{MPa}$, respectively, and the sample after partial recrystallization showed slightly lower fatigue limit of $500 \mathrm{MPa}$.
\end{abstract}

K e y w or d s: TWIP-steel, deformation twinning, microstructure, mechanical properties, fatigue

\section{Introduction}

High-Mn steel with twinning induced plasticity effect (TWIP) has captured the industry attention due to its excellent combination of mechanical properties [1-3]. The TWIP-effect is attributed to the formation of deformation twins with nanometer thickness. The deformation twinning develops in steel with medium stacking fault energy ranging from 20 to $40 \mathrm{~mJ} \mathrm{~m}^{-2}$ [4], which in turn depends on the chemical composition. The extensive formation of nanotwins leads to the so-called dynamic Hall-Petch effect resulting in an exceptionally high strain hardening [5]. Despite great advantages of TWIP steels, they have one common shortcoming that is low yield strength in comparison with modern high strength steels. The yield strength can be improved in several different ways, e.g. cold working followed by heat treatment. Some work on recovery annealing of cold worked steels
$[6,7]$ proved this method to be useful to enhance strength-plasticity combination. The closely spaced twin boundaries, which were produced by deformation twinning during cold rolling, remain almost unchanged during recovery annealing and, hence, contribute to the yield strength, while lowered dislocation density due to recovery promotes the plasticity. Fatigue limit is one of the most important criteria determining the quality of components and structures. More than $90 \%$ of all fractures are caused by fatigue in service. Numeral works have been carried out to study the recrystallization kinetics and texture after thermomechanical treatment and their effect on the tensile strength [8,9], but only a little attention has been paid to fatigue resistance of cold worked and annealed high-Mn steel with TWIP-effect [10-13].

The present work aims to obtain more data on structure-property relation including fatigue behavior of TWIP steels subjected to cold working followed by

\footnotetext{
*Corresponding author: tel./fax: +7-4722-585456; e-mail address: kusakin@bsu.edu.ru
} 
Table 1. Chemical composition of the investigated steel in wt.\%

\begin{tabular}{cccccccc}
\hline $\mathrm{C}$ & $\mathrm{Mn}$ & $\mathrm{Al}$ & $\mathrm{Si}$ & $\mathrm{N}$ & $\mathrm{S}$ & $\mathrm{P}$ & $\mathrm{Fe}$ \\
\hline 0.58 & 17.9 & 0.044 & 0.033 & 0.083 & 0.004 & 0.007 & bal. \\
\hline
\end{tabular}

recovery and partial recrystallization. Biaxial forging was selected as an advanced technique for processing of austenitic steels [14-16].

\section{Experimental}

A high-Mn TWIP steel with a nominal chemical composition given in Table 1 denoted as Fe$-18 \mathrm{Mn}-0.6 \mathrm{C}-0.1 \mathrm{~N}$ was solution annealed at $1273 \mathrm{~K}$ for $4 \mathrm{~h}$ and then forged at $1273 \mathrm{~K}$ followed by air cooling. Then, the steel samples with dimensions of $15 \times 25 \times 100 \mathrm{~mm}^{3}$ were subjected to biaxial forging $(\mathrm{BF})$ at room temperature with a pass strain of about 0.25 ; the total true strain was about 0.5 . Some forged samples were annealed at $673 \mathrm{~K}(\mathrm{BF}+\mathrm{A} 400 \mathrm{C})$ or $873 \mathrm{~K}(\mathrm{BF}+\mathrm{A} 600 \mathrm{C})$ for $1 \mathrm{~h}$. For structural characterization, the thin foils of $3 \mathrm{~mm}$ diameter were cut out parallel to the final compression axis and ground to $0.1 \mathrm{~mm}$ thickness. Then, the discs were polished using a double-jet TENUPOL-5 electrolytic polisher at a voltage of $20 \mathrm{~V}$ at room temperature using an electrolyte containing $10 \%$ perchloric acid and $90 \%$ acetic acid. The foils were examined using a JEOL JEM-2100 transmission electron microscope (TEM) operated at an acceleration voltage of $200 \mathrm{kV}$. The crystallographic features of the microstructure were determined using high-resolution electron back-scatter diffraction (EBSD) with a Quanta 600FEG scanning electron microscope. The orientation imaging microscopy (OIM) micrographs were obtained on the different areas of the longitudinal sections with a scan step of $50 \mathrm{~nm}$ and then subjected to a cleanup procedure, setting the minimal confidence index to 0.1 . The specimens for tensile tests and fatigue tests were cut out from cold forged and annealed samples. The tensile tests were carried out on the flat specimens with the gage length of $12 \mathrm{~mm}$, a width of $3 \mathrm{~mm}$ and a thickness of $1.5 \mathrm{~mm}$. The tensile tests were performed at a constant rate of $2 \mathrm{~mm} \mathrm{~min}^{-1}$. At least 2 samples were tested to obtain each data point. For fatigue tests, cylindrical specimens with a diameter of $5 \mathrm{~mm}$ and a gage length of $25 \mathrm{~mm}$ were used. Fatigue tests were carried out with an asymmetric loading cycle with a minimum to the maximum tension ratio $R=0.1$. The tests were conducted using a universal servo-hydraulic testing machine Instron 8801. The cyclic load frequency was $50 \mathrm{~Hz}$.

\section{Microstructure evolution}

Cold biaxial forging with 0.5 true strain resulted in the development of twinned microstructure as can be seen in Figs. 1a and 2a. The deformation twins formed as $\sim 2$ micron thick bundles (Fig. 1a) with individual twin thickness of $20 \mathrm{~nm}$ (Fig. 2a). The heat treatment at $673 \mathrm{~K}$ for $1 \mathrm{~h}$ did not change remarkably the structure evolved during biaxial forging, indicating that the recovery processes only took place. Figure $1 \mathrm{~b}$ shows the austenite grains with deformation twins similar to those in Fig. 1a. Figure $2 \mathrm{~b}$ represents a TEM image of the twinned area of the specimen annealed at $673 \mathrm{~K}$. It is clearly seen in Fig. $2 \mathrm{~b}$ that the deformation twins belonging to different twinning systems remain unchanged during recovery annealing at $673 \mathrm{~K}$. An increase in the annealing temperature to $873 \mathrm{~K}$ resulted in the partially recrystallized structure as shown in Fig. 1c. The new fine austenitic grains with quite a low dislocation density, as well as work hardened regions with high density of deformation twins were found in the microstructure after $1 \mathrm{~h}$ annealing at $873 \mathrm{~K}$ (Fig. 2c). The total fraction of recrystallized grains in the specimen annealed at $873 \mathrm{~K}$ was found to be about $10 \%$, and the mean size of recrystallized grains was $2 \pm 0.5 \mu \mathrm{m}$.

Figures 1d-f represent the kernel average misorientation (KAM) maps for OIM micrographs in Figs. 1ac. The color-scale-coded KAM maps are plotted on the basis of the first neighbor kernel parameter with a maximum misorientation angle of $5^{\circ}$. The blue color displays misorientations less than $1^{\circ}$, green between $1^{\circ}$ and $2^{\circ}$, yellow between $2^{\circ}$ and $3^{\circ}$, orange between $3^{\circ}$ and $4^{\circ}$, and red between $4^{\circ}$ and $5^{\circ}$. The KAM map of the sample subjected to biaxial forging (Fig. 1d) reveals the large internal distortions. The huge areas of yellow to red colors in Fig. 1d indicate the high dislocation densities corresponding to work hardening by cold biaxial forging. Annealing at $673 \mathrm{~K}$ during $1 \mathrm{~h}$ led to recovery processes, which is proved in Fig. 1e by large "blue-green" areas with kernel average misorientation less than $2^{\circ}$. After $873 \mathrm{~K}$ annealing during $1 \mathrm{~h}$, the "blue" areas in KAM map expanded while "red" areas almost disappeared (Fig. 1f) that indicates remarkable release of internal distortions and dislocations. Moreover, the new grains, which are almost free of any internal distortions (left-bottom in Fig. 1f), developed in this sample as a result of partial recrystallization.

\section{Mechanical properties}

The present Fe-18Mn-0.6C-0.1N TWIP steel in the initial state showed the yield strength (YS) and the ultimate tensile strength (UTS) of 325 and $780 \mathrm{MPa}$, respectively, and total elongation of $47 \%$, which was al- 


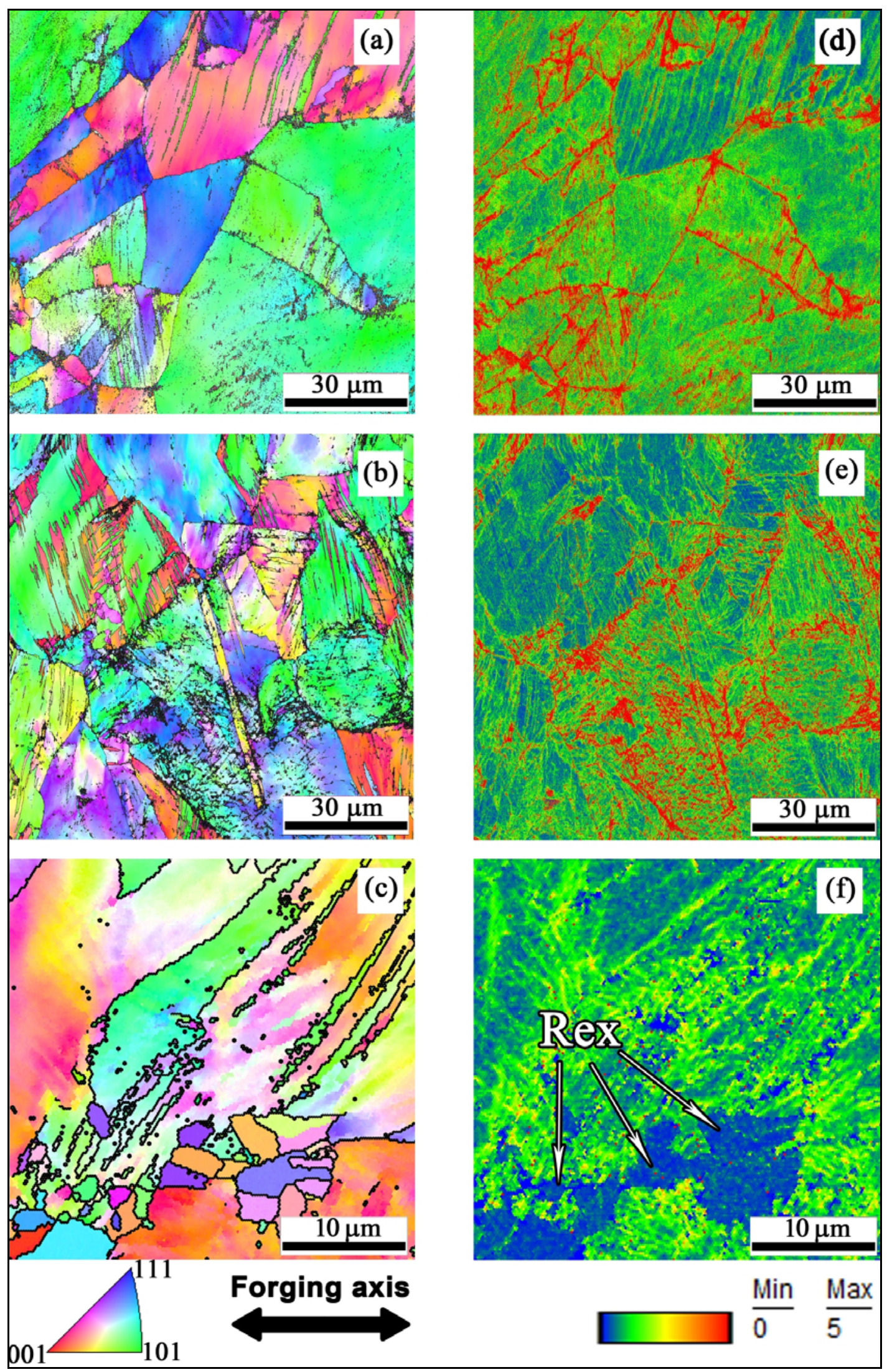

Fig. 1. OIM micrographs $(\mathrm{a}-\mathrm{c})$ and KAM maps $(\mathrm{d}-\mathrm{f})$ of microstructures and the distribution of the grain boundary misorientations developed in Fe-18Mn-0.6C-0.1N steel through: (a) biaxial forging (BF), (b) biaxial forging and annealing at $673 \mathrm{~K}(\mathrm{BF}+\mathrm{A} 400 \mathrm{C})$; (c) biaxial forging and annealing at $873 \mathrm{~K}(\mathrm{BF}+\mathrm{A} 600 \mathrm{C})$. The inverse pole figures are indicated by the forging axis. The arrows in (f) indicate recrystallized grains. 

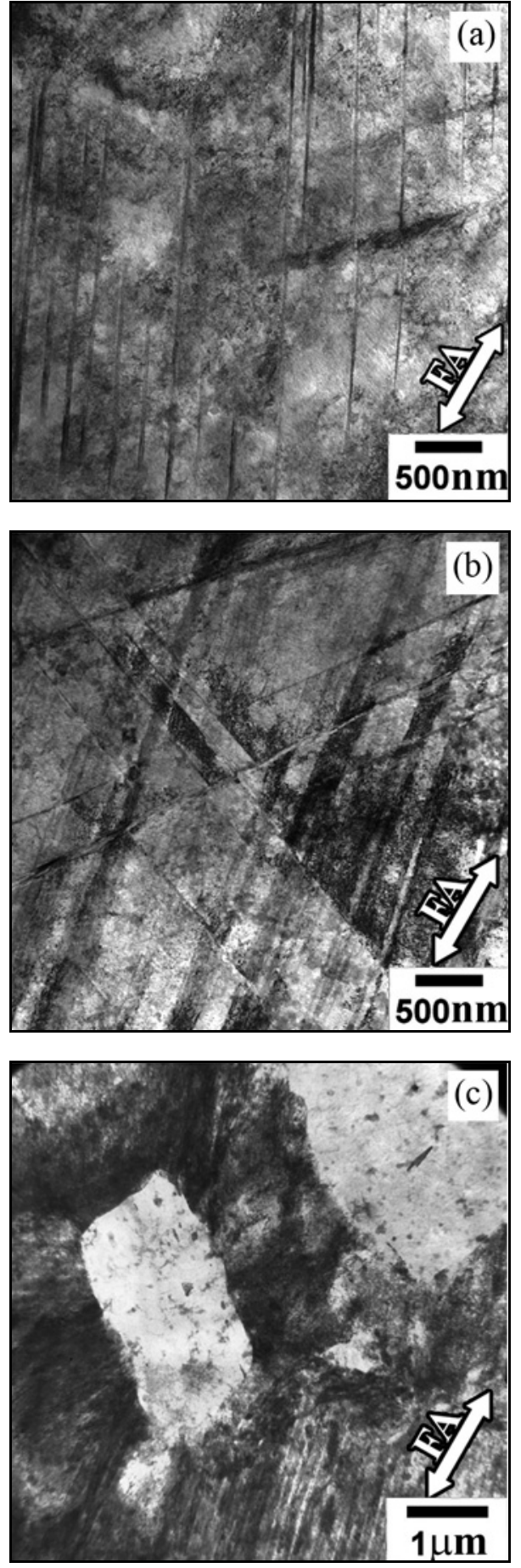

Fig. 2. TEM images of microstructures developed by (a) $\mathrm{BF},(\mathrm{b}) \mathrm{BF}+\mathrm{A} 400 \mathrm{C}$, (c) $\mathrm{BF}+\mathrm{A} 600 \mathrm{C}$. FA indicates the axis of the last forging pass.

most uniform as can be seen in Fig. 3a. The cold forged sample showed quite a small uniform elongation and necked just after reaching the yield point. The yield strength and the ultimate tensile strength of the steel after cold biaxial forging were 1320 and $1540 \mathrm{MPa}$, respectively, while the total elongation was $6 \%$. Recov-
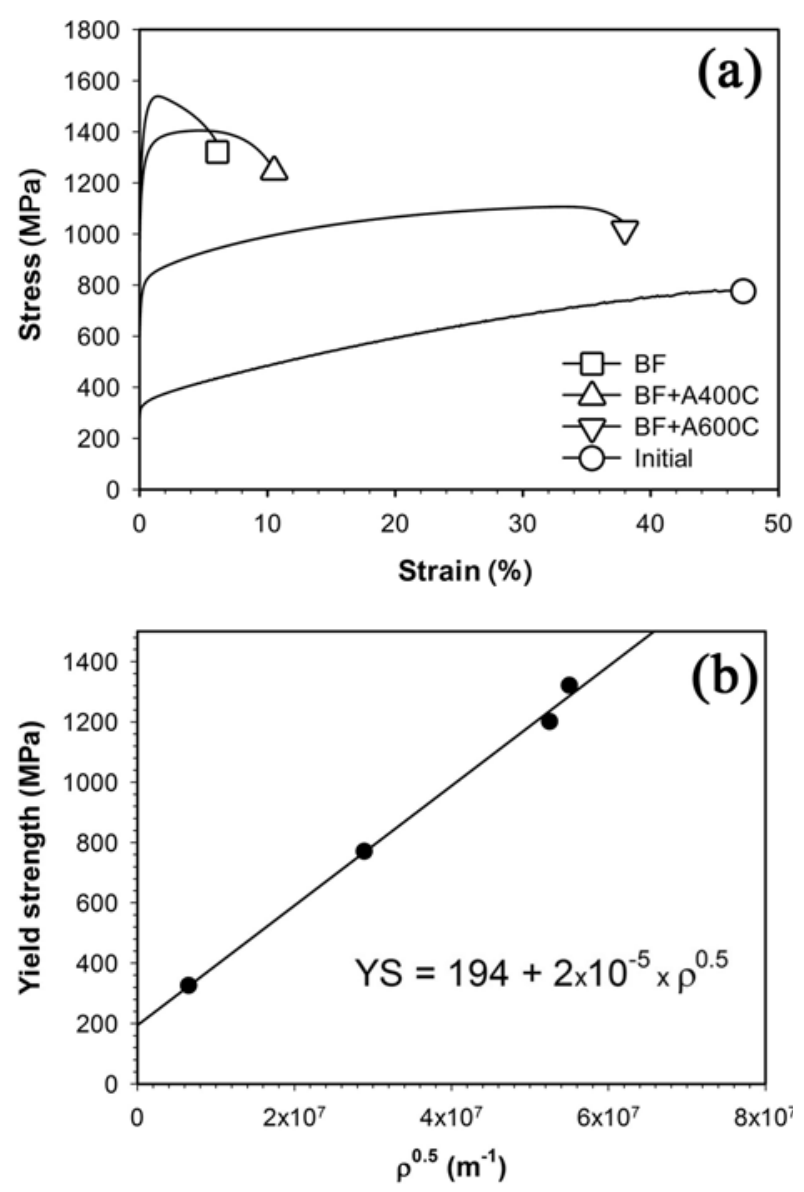

Fig. 3. (a) Stress-strain curves and (b) yield strength vs. square root of dislocation density plots for Fe-18Mn0.6C-0.1N steel specimens after different thermomechanical treatments.

ery annealing at $673 \mathrm{~K}$ of the forged material resulted in a small decrease in the yield strength and the ultimate tensile strength to 1200 and $1410 \mathrm{MPa}$, respectively, and the total elongation increased to $10 \%$. An increase of annealing temperature to $873 \mathrm{~K}$ resulted in a quite interesting combination of mechanical properties. Namely, the yield strength was $770 \mathrm{MPa}$; the ultimate tensile strength was $1110 \mathrm{MPa}$ and the elongation comprised about $40 \%$ with uniform elongation of about $35 \%$ (Fig. 3a).

The strengthening of metallic materials during cold working is generally attributed to an increase in the dislocation density [17]. The dislocation densities in the present steel samples can be estimated from kernel average misorientation data obtained from EBSD images using Frank's equation, Eq. (1):

$$
\theta \approx 2 \sin \frac{\theta}{2}=\frac{N b}{h},
$$

where $\theta$ is the misorientation created by a wall consisting of $N$ dislocations of height $h$, and $b$ is the Burgers 
Table 2. Values of physical parameters in Eq. (3) and calculated dislocation density

\begin{tabular}{lrrr}
\hline Specimen & $\theta / h\left(\mathrm{~m}^{-1}\right)$ & $b(\mathrm{~m})$ & $\rho\left(\mathrm{m}^{-2}\right)$ \\
\hline Initial & $5.45 \times 10^{5}$ & $2.54 \times 10^{-10}$ & $4.3 \times 10^{13}$ \\
$\mathrm{BF}$ & $3.84 \times 10^{7}$ & $2.54 \times 10^{-10}$ & $3 \times 10^{15}$ \\
$\mathrm{BF}+\mathrm{A} 400 \mathrm{C}$ & $3.5 \times 10^{7}$ & $2.54 \times 10^{-10}$ & $2.75 \times 10^{15}$ \\
$\mathrm{BF}+\mathrm{A} 600 \mathrm{C}$ & $1.06 \times 10^{7}$ & $2.54 \times 10^{-10}$ & $8.4 \times 10^{14}$ \\
\hline
\end{tabular}

Table 3. Values of physical parameters in Eq. (6)

\begin{tabular}{ccccc}
\hline$\alpha$ & $M$ & $G(\mathrm{MPa})$ & $b(\mathrm{~m})$ & $\sigma_{0}(\mathrm{MPa})$ \\
\hline 0.36 & 3 & 72000 & $2.54 \times 10^{-10}$ & 194 \\
\hline
\end{tabular}

vector. In EBSD experiments, distance $h$ corresponds to the step size of the scanning. The dislocation density $\rho$ is then given by the ratio of the dislocation number per surface area, Eq. (2):

$$
\rho=\frac{N}{S}
$$

where the surface area of the hexagon $S$ (scanning geometry) is $S=\sqrt{3} h^{2} / 2$. It follows that the dislocation density can be estimated from the following relationship:

$$
\rho=\frac{2 \theta}{\sqrt{3} h b} .
$$

The values used for dislocation density calculations are given in Table 2 .

The relationship between the yield strength and the dislocation density of the Fe-18Mn-0.6C- $0.1 \mathrm{~N}$ steel is displayed in Fig. 3b. The yield strength (YS) shows a linear dependence on the dislocation density square root and can be expressed as follows:

$$
\mathrm{YS}=194+2 \times 10^{-5} \sqrt{\rho} .
$$

Generally, the flow stress in terms of the resolved shear stress $(\tau)$ relates to the square root of dislocation density $[17,18]$ :

$$
\tau=\tau_{0}+\alpha G b \sqrt{\rho},
$$

where $\tau_{0}$ is the friction stress, $\alpha$ is a constant, $G$ is the shear modulus, and $b$ is Burgers vector. In terms of tensile stress, taking $\sigma=M \tau$, the flow stress $(\sigma)$ is estimated by the following relationship:

$$
\sigma=\sigma_{0}+\alpha M G b \sqrt{\rho}
$$

where $M$ is the average Taylor factor. Then, the coefficients in Eq. (4) can be expressed in terms of parameters used in Eq. (6). The values of these physical parameters used in Eq. (6) for Fe-18Mn-0.6C-0.1N
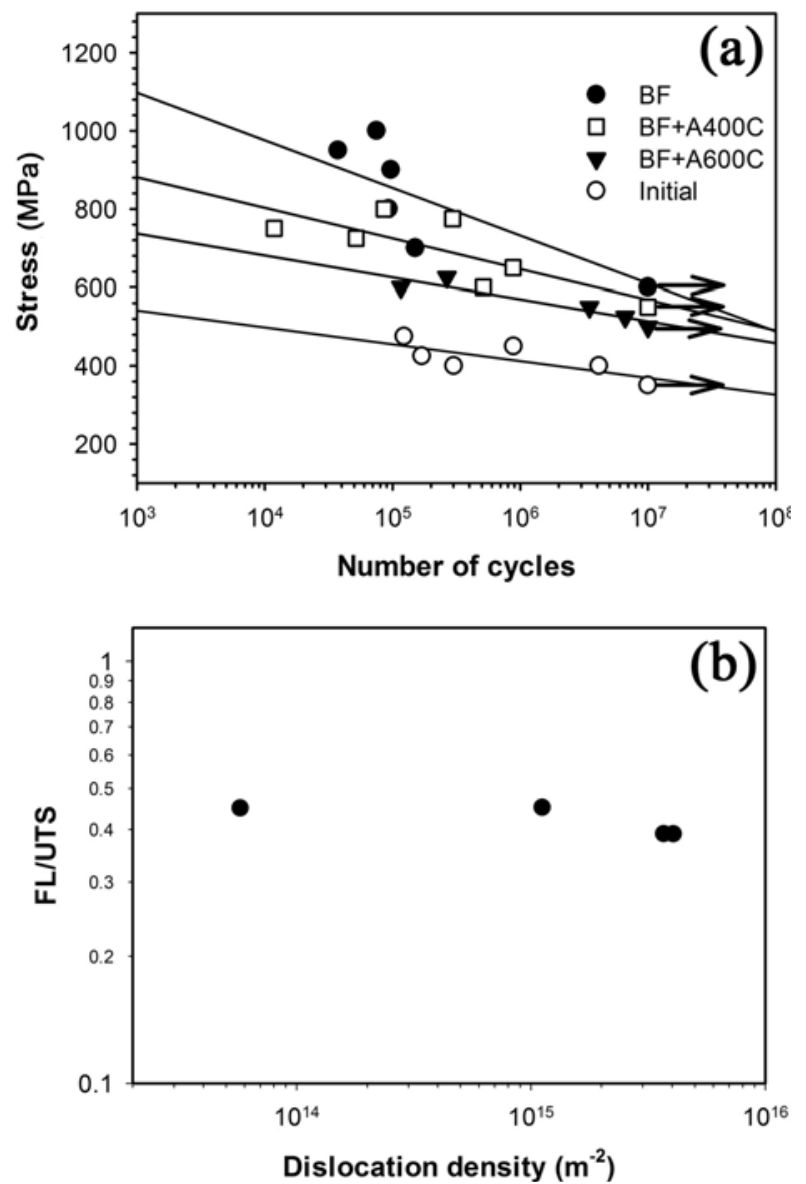

Fig. 4. (a) Stress amplitude-fatigue life data and (b) fatigue limit normalized by ultimate tensile strength (FL/UTS) as a function of dislocation density of Fe-18Mn-0.6C-0.1N steel specimens after different thermomechanical treatments. The arrows in (a) indicate no failure at given stress amplitude after $10^{7}$ cycles.

TWIP steel are given in Table 3 . The numerical factor of $\alpha=0.36$ is almost the same as those reported in other theoretical and experimental studies on dis- 
location strengthening [19-21]. This suggests that the yield strength of the present steels with different microstructures, i.e. work hardened, recovery annealed and partially recrystallized, can be expressed by a unique function of dislocation strengthening.

Figure $4 \mathrm{a}$ shows the experimental fatigue data for the Fe- $18 \mathrm{Mn}-0.6 \mathrm{C}-0.1 \mathrm{~N}$ steel. The specimens in the initial state showed fatigue limit (FL) of $350 \mathrm{MPa}$ corresponding to $10^{7}$ cycles. The specimens with asforged and recovered structures exhibited fatigue limits of 600 and $550 \mathrm{MPa}$, respectively, while the specimen after partial recrystallization is characterized by a slightly lower fatigue limit of $500 \mathrm{MPa}$.

It can be seen from the fatigue data in Fig. 4a that the recovered structure provides lower fatigue resistance at cycle number below $10^{7}$ cycles. As the deformation twins remain stable until recrystallization [22-24], the difference between these two conditions is the dislocation density only. Therefore, the dislocation density affects remarkably the fatigue resistance in work hardened and recovered TWIP steels.

Figure $4 \mathrm{~b}$ represents the relationship between the fatigue limit normalized by ultimate tensile strength (FL/UTS) and the dislocation density. Commonly, the fatigue limit of steels can be roughly related to the tensile strength, so that the ratio of FL/UTS is generally between 0.4 and 0.6 [25]. This rule is applicable to all the present steel samples subjected to cold forging and various annealing treatments as can be seen in Fig. $4 \mathrm{~b}$. It is worth noting that despite large differences in processing conditions and the dislocation densities, the FL/UTS ratio remains almost unchanged and stays in the range of $0.42 \pm 0.03$ that is slightly lower than values reported for different TWIP-steels in recrystallized conditions [12].

\section{Summary}

The influence of cold forging and annealing on the microstructure evolution and mechanical properties of a high-Mn TWIP steel (Fe-18Mn-0.6C-0.1N) was investigated. The main conclusions can be drawn as follows:

1. Cold biaxial forging with a total true strain of 0.5 resulted in the development of twinned microstructure with a high dislocation density of $3 \times 10^{15} \mathrm{~m}^{-2}$. The deformation twins formed as $\sim 2$ micron thick bundles with individual twin thickness of $20 \mathrm{~nm}$. The heat treatment at $673 \mathrm{~K}$ for $1 \mathrm{~h}$ favored only recovery processes, whereas annealing at $873 \mathrm{~K}$ resulted in partially recrystallized microstructure with a grain size of 2 microns and their fraction of 0.1 .

2. The steel showed YS $=325 \mathrm{MPa}$ and UTS $=$ $780 \mathrm{MPa}$ with total elongation of $47 \%$ in the initial state and YS $=1320 \mathrm{MPa}$, UTS $=1540 \mathrm{MPa}$ with the total elongation of $6 \%$ after multiple-stage cold forg- ing. Recovery annealing of the forged material resulted in a decrease of YS and UTS to 1200 and $1410 \mathrm{MPa}$, respectively, and the total elongation increased to $10 \%$. Further increase of annealing temperature resulted in an attractive combination of mechanical properties: YS $=770 \mathrm{MPa}$, UTS $=1110 \mathrm{MPa}$ with uniform elongation about $35 \%$. The yield strength of the steel in different conditions can be described as follows: YS $=194+2 \times 10^{-5} \sqrt{\rho}$.

3. The steel in the initial state showed FL $=$ $350 \mathrm{MPa}$ at $10^{7}$ cycles. As-forged and recovered specimens showed FL of $600 \mathrm{MPa}$ and $550 \mathrm{MPa}$ at $10^{7}$ cycles, respectively. The specimen after partial recrystallization showed slightly lower FL of $500 \mathrm{MPa}$. The FL/UTS ratio of $0.42 \pm 0.03$ remains almost unchanged.

\section{Acknowledgement}

Authors are grateful to staff of Joint Research Centre, Belgorod State University, for their assistance with structural and mechanical characterizations.

\section{References}

[1] Bouaziz, O., Allain, S., Scott, C. P., Cugy, P., Barbier, D.: Curr. Opin. Solid State Mater. Sci., 15, 2011, p. 141. doi:10.1016/i.cossms.2011.04.002

[2] Chen, L., Zhao, Y., Qin, X.: Acta Metall. Sin. (English Lett.), 26, 2013, p. 1. doi:10.1007/s40195-012-0501-x

[3] Kim, H.-S., Suh, D.-W., Kim, N. J.: Sci. Technol. Adv. Mater., 14, 2013, 014205. doi:10.1088/1468-6996/14/1/014205

[4] Dumay, A., Chateau, J.-P., Allain, S., Migot, S., Bouaziz, O.: Mater. Sci. Eng. A, 483-484, 2008, p. 184. doi:10.1016/j.msea.2006.12.170

[5] Bouaziz, O., Guelton, N.: Mater. Sci. Eng. A, 319-321, 2001, p. 246. doi:10.1016/S0921-5093(00)02019-0

[6] Haase, C., Barrales-Mora, L. A., Molodov, D. A., Gottstein, G.: Metall. Mater. Trans. A, 44, 2013, p. 4445. doi:10.1007/s11661-013-1935-0

[7] Bouaziz, O., Scott, C. P., Petitgand, G.: Scr. Mater., 60, 2009, p. 714. doi:10.1016/j.scriptamat.2009.01.004

[8] Haase, C., Barrales-Mora, L. A., Roters, F., Molodov, D. A., Gottstein, G.: Acta Mater., 80, 2014, p. 327. doi:10.1016/j.actamat.2014.07.068

[9] Koyama, M., Lee, T.-Y., Lee, C. S., Tsuzaki, K.: Mater. Des., 49, 2013, p. 234. doi:10.1016/j.matdes.2013.01.061

[10] Nikulin, I., Sawaguchi, T., Tsuzaki, K.: Mater. Sci. Eng. A, 587, 2013, p. 192. doi:10.1016/j.msea.2013.08.061

[11] Hamada, A. S., Karjalainen, L. P., Puustinen, J.: Mater. Sci. Eng. A, 517, 2009, p. 68. doi:10.1016/j.msea.2009.03.039

[12] Hamada, A. S., Karjalainen, L. P., Ferraiuolo, A., Gil Sevillano, J., de las Cuevas, F., Pratolongo, G., Reis, M.: Metall. Mater. Trans. A, 41, 2010, p. 1102. doi:10.1007/s11661-010-0193-7 
[13] Hamada, A. S., Karjalainen, L. P.: Mater. Sci. Eng. A, 527, 2010, p. 5715. doi:10.1016/i.msea.2010.05.035

[14] Tikhonova, M., Belyakov, A., Kaibyshev, R.: Mater. Sci. Eng. A, 564, 2013, p. 413. doi:10.1016/j.msea.2012.11.088

[15] Yanushkevich, Z., Mogucheva, A., Tikhonova, M., Belyakov, A., Kaibyshev, R.: Mater. Charact., 62, 2011, p. 432. doi:10.1016/j.matchar.2011.02.005

[16] Shakhova, I., Dudko, V., Belyakov, A., Tsuzaki, K., Kaibyshev, R.: Mater. Sci. Eng. A, 545, 2012, p. 176. doi:10.1016/i.msea.2012.02.101

[17] Gottstein, G.: Physical Foundations of Materials Science. Berlin, Heidelberg, Springer 2004. doi:10.1007/978-3-662-09291-0

[18] Kocks, U. F., Mecking, H.: Prog. Mater. Sci., 48, 2003, p. 171. doi:10.1016/S0079-6425(02)00003-8

[19] Allain, S., Chateau, J.-P., Bouaziz, O.: Mater. Sci. Eng. A, 387, 2004, p. 143. $\underline{\text { doi:10.1016/j.msea.2004.01.060 }}$
[20] Soulami, A., Choi, K. S., Shen, Y. F., Liu, W. N., Sun, X., Khaleel, M. A.: Mater. Sci. Eng. A, 528, 2011, p. 1402. doi:10.1016/j.msea.2010.10.031

[21] Chinh, N. Q., Horváth, G., Horita, Z., Langdon, T. G.: Acta Mater., 2004, 52, p. 3555. doi:10.1016/j.actamat.2004.04.009

[22] Kang, S., Jung, Y.-S., Jun, J.-H., Lee, Y.-K.: Mater. Sci. Eng. A, 527, 2010, p. 745. doi:10.1016/i.msea.2009.08.048

[23] Dini, G., Najafizadeh, A., Ueji, R., Monir-Vaghefi, S. M.: Mater. Lett., 64, 2010, p. 15. doi:10.1016/j.matlet.2009.09.057

[24] Viscorova, R., Kroos, J., Flaxa, V., Wendelstorf, J., Spitzer, K. H.: In: Proceedings of IDDRG Conference. Ed.: Kergen, R. Düsseldorf, Verlag Stahleisen GmbH 2004, p. 261. ISBN 3-514-00708-X.

[25] Chapetti, M. D., Miyata, H., Tagawa, T., Miyata, T., Fujioka, M.: Mater. Sci. Eng. A, 381, 2004, p. 331. doi:10.1016/j.msea.2004.04.055 